\title{
Hermanus Magnetic Observatory: a historical perspective of geomagnetism in southern Africa
}

\author{
Pieter B. Kotzé $\mathbf{e}^{1,2}$ \\ ${ }^{1}$ South African National Space Agency, Space Science, Hermanus, South Africa \\ ${ }^{2}$ Centre for Space Research, North-West University, Potchefstroom, South Africa
}

Correspondence: Pieter B. Kotzé (pkotze@ sansa.org.za)

Received: 10 July 2018 - Revised: 6 August 2018 - Accepted: 13 August 2018 - Published: 24 August 2018

\begin{abstract}
In this paper a brief summary will be given about the historical development of geomagnetism as a science in southern Africa and particularly the role played by Hermanus Magnetic Observatory in this regard. From a very modest beginning in 1841 as a recording station at the Cape of Good Hope, Hermanus Magnetic Observatory is today part of the South African National Space Agency (SANSA), where its geomagnetic field data are extensively used in international research projects ranging from the physics of the geo-dynamo to studies of the near-Earth space environment.
\end{abstract}

\section{Introduction}

The requirements of navigation during the era of exploration, rather than any scientific interest in geomagnetism, prompted the recording of geomagnetic field components at the Cape of Good Hope even before 1600 (Kotzé, 2007). The importance of knowledge regarding the deviation of a compass needle from true north was sufficient motivation to establish a geomagnetic field recording station at the Cape in 1841. The geomagnetic field is fundamental to any research related to terrestrial and extra-terrestrial physics, and therefore the establishment of the magnetic observatory during the Polar Year 1932/1933 and later in 1941 in Hermanus was essential. Today Hermanus Magnetic Observatory forms part of the South African National Space Agency (SANSA), and participates in international projects involving Satellite missions like Ørsted (http://www.space.dtu.dk/english/research/projects/ projecdescriptions/oersted, last access: 14 May 2018), CHAMP (https://www.gfz-potsdam.de/en/section/ geomagnetism/infrastructure/champ/satellite-systems/, last access: 14 May 2018) and SWARM (https://earth.esa. int/web/guest/missions/esa-operational-eo-missions/swarm, last access: 15 May 2018), while ground observations obtained from a network of repeat stations and three other INTERMAGNET (http://www.intermagnet.org, last access: 16 May 2018) observatories at Hartebeesthoek, Tsumeb and
Keetmanshoop enable studies of secular variation patterns over southern Africa and the influence of the South Atlantic Magnetic Anomaly (e.g. Pavón-Carasco and De Santis, 2016) on the characteristics of the global geomagnetic field. This is a region where the Earth's magnetic field is approximately $25 \%$ weaker than at similar latitudes around the globe, allowing energetic particles from the radiation belts to penetrate the atmosphere to very low altitudes. This can result in radiation damage to sensitive electronics onboard low-Earth orbit satellites. The regional monitoring and research of the geomagnetic field in southern Africa are therefore important in understanding the time-varying South Atlantic Anomaly and its subsequent influence on the morphology of the global field.

\section{The early history of 1600 till 1932}

This overview of geomagnetism and its historical development in southern Africa covers a period of approximately 400 years till present (Kotzé, 2007, 2015). During the era of exploration between 1600 and 1700, visiting European-based sailors had been responsible for all early magnetic measurements in South Africa. In fact the earliest recorded observation of magnetic declination on land was made at Mossel Bay in 1595 by Cornelis de Houtman (Beattie, 1909), commander of a Dutch fleet on its way to India, who obtained a value of 
$0^{\circ}$. Earlier ship-borne measurements by the Portuguese navigator De Castro in 1538 (De Castro, 1538) indicate that the magnetic declination at the Cape was then about $6^{\circ}$ east of true north (Kotzé, 2007). The earliest determination of inclination at Cape Town was made by the French astronomer La Caille in 1751 when he set up an observatory on the shore of Table Bay with the help of the Dutch governor Ryk Tulbach (Glass, 2013).

De Freycinet, a French navigator, while on a voyage around the world, was responsible for the first complete determination of the magnetic field at Cape Town in 1818 (De Freycinet, 1842). He obtained a value of $32450 \mathrm{nT}$ for the total field strength, $-50.8^{\circ}$ for inclination as well as $26.5^{\circ}$ west of true north for declination. The first systematic observations in South Africa however resulted from the establishment, in 1841, of a worldwide network of observation stations (Kotzé, 2007). One of these stations was built on the grounds of the Royal Observatory at the Cape of Good Hope, with a Royal Artillery detachment, led by Lt Frederick Eardly-Wilmot, responsible for all measurements (Sabine, 1851). After the magnetic observatory was destroyed by fire in 1852 , a period of 80 years elapsed before an observatory concentrating on magnetic measurements was again built in South Africa. During that period magnetic declination observations were however made by surveyors at different geographical positions of the interior of the country. The first magnetic survey of the Union of South Africa was carried out by John Carruthers Beattie of the South African College in Cape Town, assisted by John Todd Morrison of the Victoria College in Stellenbosch, between 1898 and 1906 (Beattie and Morrisson, 1903). Measurements of magnetic declination, inclination and horizontal intensity were made using Kew magnetometers and Dover dip circles magnetic declination (Kotzé, 2014). These 336 observations were recently used to derive a spherical cap harmonic field model for southern Africa for 1903.5 , valid between 25 and $35^{\circ} \mathrm{S}$ and between 17 and $32^{\circ} \mathrm{E}$ (Kotzé, 2014). This model now serves as the first historical regional field model for southern Africa. A significant contribution to geomagnetism research in southern Africa was made by Grindley of the University of Cape Town, who compiled a set of isomagnetic charts based on observations at 700 positions reduced to epoch 1930.5 (Grindley, 1947).

\section{The period from 1932 till present}

\subsection{Magnetic field observations in southern Africa}

The Polar Year of 1932-1933 prompted the establishment of a magnetic observatory at the University of Cape Town in 1932 under the leadership of Alexander Ogg (Van Wijk, 1948). Carruthers Beattie, also a physicist, who was by then Principal of the University of Cape Town, appreciated the need for such observations and provided full support. International organizations like the Carnegie Institution in Wash-

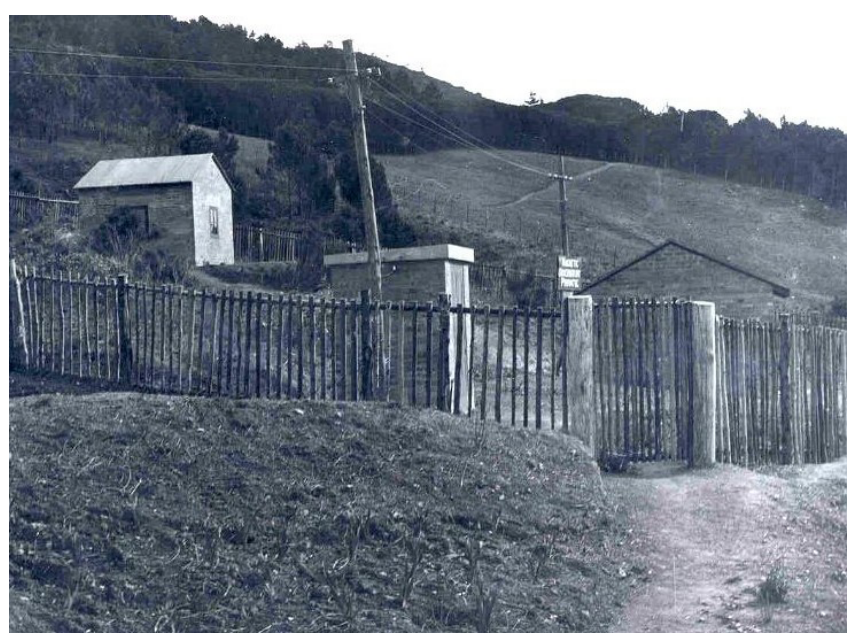

Figure 1. The magnetic observatory established close to the Department of Physics at the University of Cape Town in 1932.

ington provided grants for buildings and the loan of instruments for standard observations by the International Commission for the Polar Year. Figure 1 shows the buildings on the campus of the university of Cape Town that were constructed to serve as a magnetic observatory.

With the assistance of members of the staff of the Physics Department, it was eventually possible to start the observation activities on 5 August 1932 (Ogg, 1939). Establishing the magnetic observatory on a temporary basis for the duration of the Polar Year was only the first step towards a permanent facility. In May 1933 the International Commission for the Polar Year passed the following unanimous resolution at a meeting in Copenhagen (https://doi.org/1029/TE038I003P00243):

"The Commission considers it highly desirable that the magnetic station of Cape Town, South Africa, should be made a permanent station because of its situation in the Southern Latitude, from which, considering the network of existing stations, magnetic observations are particularly required."

In order to secure the establishment of the magnetic observatory on a permanent basis, the University of Cape Town appointed Ogg, on his retirement, as director of the observatory. In the meantime UCT had also started negotiations with the South African Department of Lands, which was responsible for geophysical observations, on a possible transfer of the magnetic observatory to that department. These negotiations culminated in the formation of a Magnetic Branch of the Trigonometric Survey Office of the Department of Lands in 1937. Ogg was appointed as Magnetic Adviser to head this branch.

The subsequent electrification of the suburban railway network however created a disturbing influence, to the ex- 


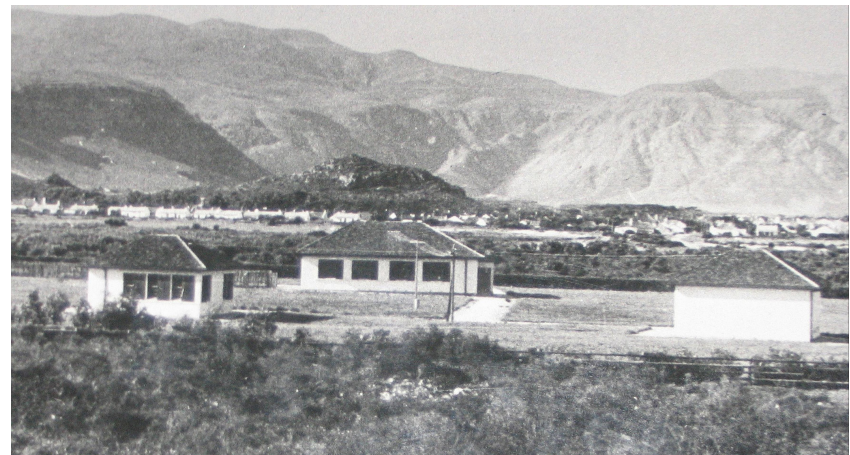

Figure 2. The magnetic observatory as it looked when established in Hermanus in 1941.

tent that accurate observations became almost impossible. A new site was identified in Hermanus, because it was sufficiently remote from electric railway disturbances and had been proved by a magnetic survey to be suitable to host a magnetic observatory as the underlying geology of the area consists exclusively of Table Mountain sandstone with negligibly small magnetic gradients. Today the site is protected by law to ensure the continuation of scientific activities. Hermanus Magnetic Observatory officially started to function on 1 January 1941 with Ogg as the head. Simultaneous observations were made at Hermanus and Cape Town for the last few months of 1940 to preserve continuity during the transfer. The first buildings of Hermanus Magnetic Observatory in 1941 can be seen in Fig. 2. Since 1941 many buildings have been added to the original infrastructure. At present a wellequipped library, electronics workshop, a mechanical workshop, lecture rooms, as well as offices for staff and students form part of the infrastructure. The complex is situated on a square piece of undeveloped land with a size of 16 ha to protect the sensitive instruments from unwanted background signals. The present main building can be seen in Fig. 3 .

A major undertaking during the period 1960-2005 was the establishment of other magnetic observatories in southern Africa (Kotzé, 2015). In 1964 an opportunity arose to establish a magnetic observatory on the premises of the Forschungsstation Jonathan Zenneck, a permanent ionospheric observation station of the Max Planck Institut für Aeronomie (Lindau, Germany) outside Tsumeb in Namibia as part of South Africa's contribution to the IQSY Programme (International Quiet Sun Years, 1964-1965). In view of the strategic position of the observatory in the north of Namibia, it was decided to continue with magnetic recordings at Tsumeb (Van Wijk and Scheepers, 1969) after the termination of IQSY. Another magnetic observatory with instruments provided by the German GeoForshungsZentrum in Potsdam was established at Keetmanshoop in Namibia in 2005 (Linthe et al., 2007). Other recording stations were also established in South Africa - one at Hartebeesthoek in 1972 (Kühn, 1978), located approximately $55 \mathrm{~km}$ west

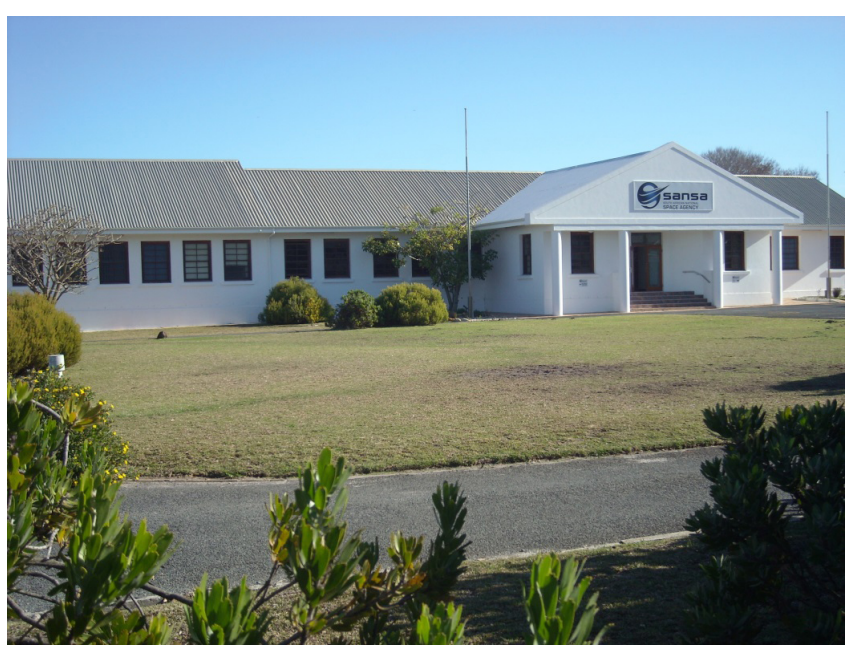

Figure 3. The present main building of the SANSA Space Science in Hermanus, current home institution of Hermanus Magnetic Observatory.

of Pretoria, and the other at Grahamstown in 1974. Problems from man-made noise at Grahamstown eventually led to the closure of the station in 1980. At the moment Hermanus (HER), Hartebeesthoek (HBK), Tsumeb (TSU) and Keetmanshoop (KMH) are INTERMAGNET (INTErnational Real-time MAGnetic Observatory NETwork) observatories (Love and Chulliat, 2013).

The first instruments that were installed at Hermanus for the continuous registration of magnetic field components were the photographically recording Askania magnetic variometers, designed by La Cour (La Cour, 1926), using sets of Helmholtz coils to calibrate the sensitivities of the instruments. A photo of the Askania variometer that was used in Hermanus since 1932 for recording the $H, D$ and $Z$ components of the geomagnetic field can be seen in Fig. 4. These instruments, using photographic recording paper, mounted on a rotating drum, had to be changed exactly every $24 \mathrm{~h}$, each day of the year.

During the early 1990s the Askania analogue recording instruments were phased out and replaced with digital magnetometers based on electronic fluxgate technology recording the three $H, D$ and $Z$ components of the geomagnetic field with a resolution of $0.1 \mathrm{nT}$ at $1 \mathrm{~s}$ intervals. At present the backbones of the magnetic recording instruments at all four observatories are the FGE type three-axis fluxgate instruments as built and supplied by the Danish Space Institute (http://www.space.dtu.dk/English/Research/Instruments_ Systems_Methods/3-axis_Fluxgate_Magnetometer_Model_ FGM-FGE.aspx, last access: 11 June 2018). All of the abovementioned instruments do not provide absolute values, and had to be corrected for baseline shifts on a regular basis. One such instrument was the Schmidt declinometer which was used at Hermanus to determine the absolute value of magnetic declination as recorded by the Askania variometer 


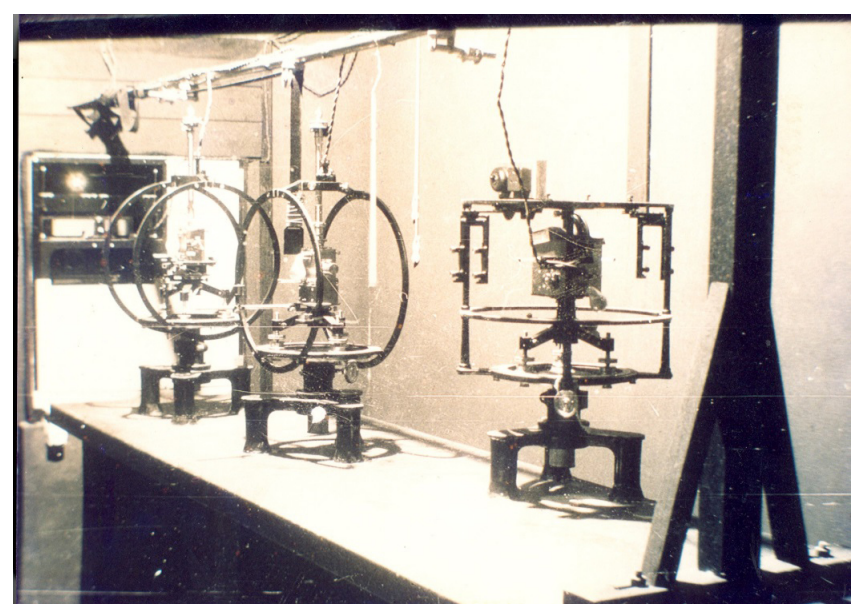

Figure 4. A photographic-recording Askania variometer with its set of Helmholtz coils.

accurately to within $1 \mathrm{~s}$ of an arc, shown in Fig. 5. At present an electronic declination-inclination fluxgate (DI flux) theodolite instrument is used to determine absolute angles of declination and inclination for the fluxgate-based instruments. These instruments consist of a non-magnetic theodolite equipped with a single-axis fluxgate sensor. These angles are taken in positions where the fluxgate signal is zero. In addition, proton precession and Overhauser scalar magnetometers are used in order to determine the final and absolute baselines at the observatories.

One of the major contributions to geomagnetism in southern Africa was the establishment of a long-term magnetic secular variation programme in 1938-1939 (Kotzé, 2015). The programme consisted initially of 44 permanent field stations covering, with a fairly uniform distribution, the whole of South Africa, Namibia and Botswana. To ensure exact reoccupation during subsequent surveys, pillars were erected at each field station with precise geographical coordinates (latitude, longitude, altitude above sea level). The first occupation of this network of stations of the magnetic observatory took place in 1947-1948, thereafter in 1952-1953, and again in 1961, after which they were occupied at 5-yearly intervals till 2000. The average distance between these repeat stations is approximately $300 \mathrm{~km}$. Since 2000 fewer stations have been included, as the emphasis changed to annual secular variation measurements. A total of 40 repeat stations currently form the backbone of the annual field surveys, as shown in Fig. 6 .

These pillars, about $1.2 \mathrm{~m}$ tall and constructed from nonmagnetic concrete, are located on private farms, game reserves, airports, and even golf courses to provide an even spatial distribution over southern Africa and to be far away from human activities like roads carrying high traffic volumes. In this regard the network of secular variation stations complies with international standards and procedures.

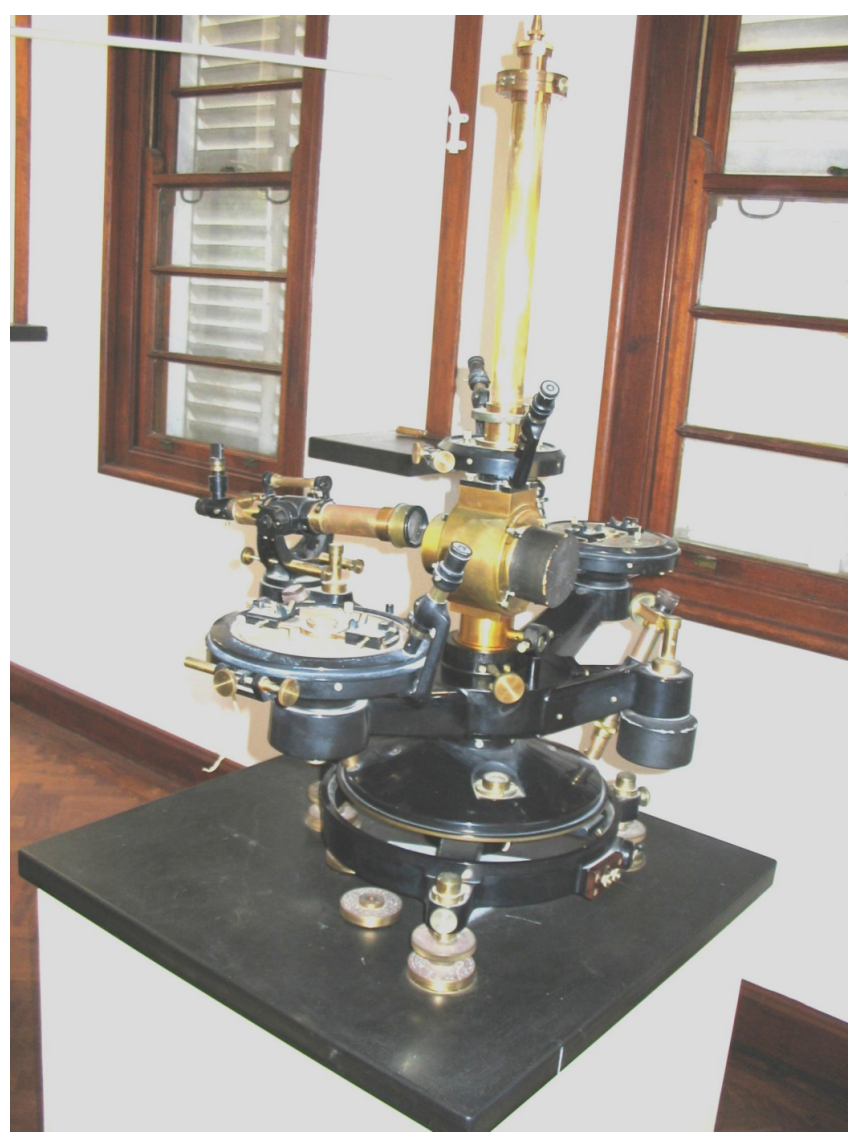

Figure 5. A Schmidt declinometer for determining the absolute value of declination.

\subsection{Activities in other areas and disciplines}

The decades that followed World War II saw a gradual growth in both the routine and scientific research activities at the observatory (Kotzé, 2015). Participation in the internationally coordinated scientific programmes such as the International Geophysical Year (IGY) in 1957, the International Quiet Sun Years (IQSY) in 1964-1965 and the International Magnetospheric Study (IMS) in 1976-1978 contributed in several ways to the development of an active and productive research programme at Hermanus. The IGY of 1957 1959 in particular provided the incentive for Hermanus Magnetic Observatory to expand its activities and set up a number of new instruments in collaboration with other institutions. As part of its contribution to this IGY, South Africa participated in the proposed world-wide cosmic-ray monitoring programme. A meson telescope and a Simpson neutron monitor were constructed by physicists at Stellenbosch and Potchefstroom universities respectively and then installed at Hermanus Magnetic Observatory for operation. The Simpson neutron monitor, named after its inventor John Simpson in 1948 (Simpson, 2000) is a large instrument and weighs about 36 ton. The meson telescope consisted of a special array of Geiger counters and lead slabs to enable only the reg- 


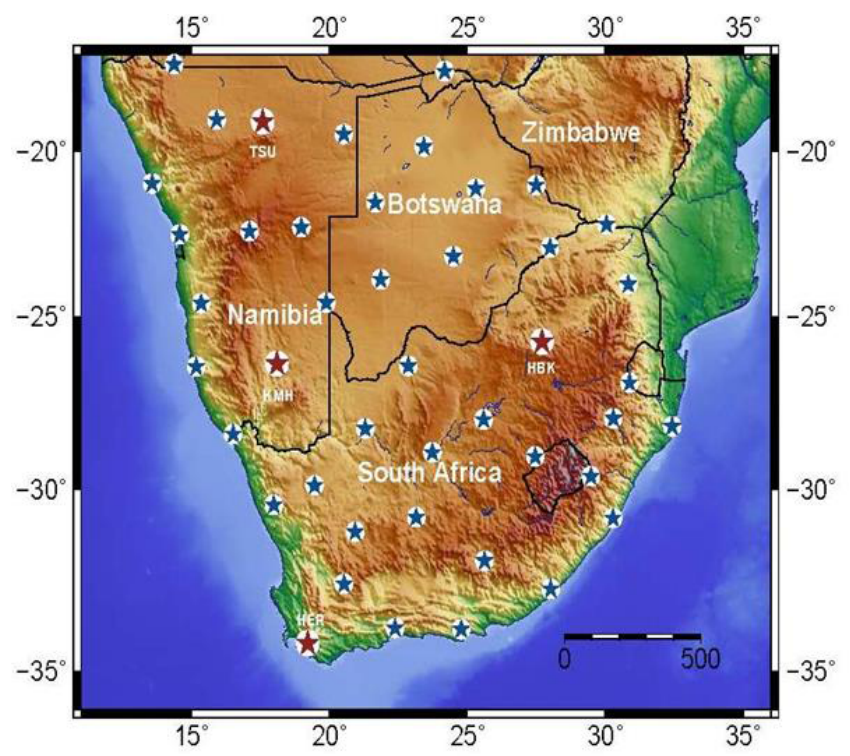

Figure 6. A map of southern Africa showing the positions of the four INTERMAGNET observatories, Hermanus (HER), Hartebeesthoek (HBK), Keetmanshoop (KMH) and Tsumeb (TSU) (red stars), as well as the positions of the field survey repeat stations (blue stars).

istration of cosmic ray mesons incident on Earth above an azimuthal angle of $45^{\circ}$. As such the neutron monitor at Hermanus is one on the longest serving neutron monitors in the world. During the IGY of 1957, Norway established a base in Queen Maud Land, Antarctica, where, amongst others, geomagnetic field recordings were made using Askania La Cour variographs (Kotzé, 2015). South Africa, which was also a signatory to the Antarctic Treaty, took over the Norway Station base in 1960 and Hermanus Magnetic Observatory assumed responsibility for the geomagnetic field recordings. As a result of these activities, the observatory formed part of the first South African Antarctic Expedition (SANAE 1) in 1960. Later teams overwintered at SANAE I, SANAE II and SANAE III, built on the Fimbul Ice Shelf near Blåskimen. Built on the moving ice shelf, these stations inevitably got buried, and eventually broke off as part of icebergs drifting away. Successive stations were always repositioned at the same geographical position of $70^{\circ} 18^{\prime} \mathrm{S}, 2^{\circ} 22^{\prime} \mathrm{W}$. SANAE IV was built on the Vesleskarvet rock outcrop in order to have a base with a longer lifetime. The first team to overwinter at SANAE IV was SANAE 36 in 1997. The base has been manned uninterruptedly since then.

The observatory has been involved in the running and maintenance of instruments on behalf of other institutions and organizations. A seismograph for the detection of earthquakes operated till 1985 on the premises of Hermanus Magnetic Observatory. This seismograph formed part of a national network of seismographs, belonging to the Geological Survey of South Africa. In addition to the neutron moni-

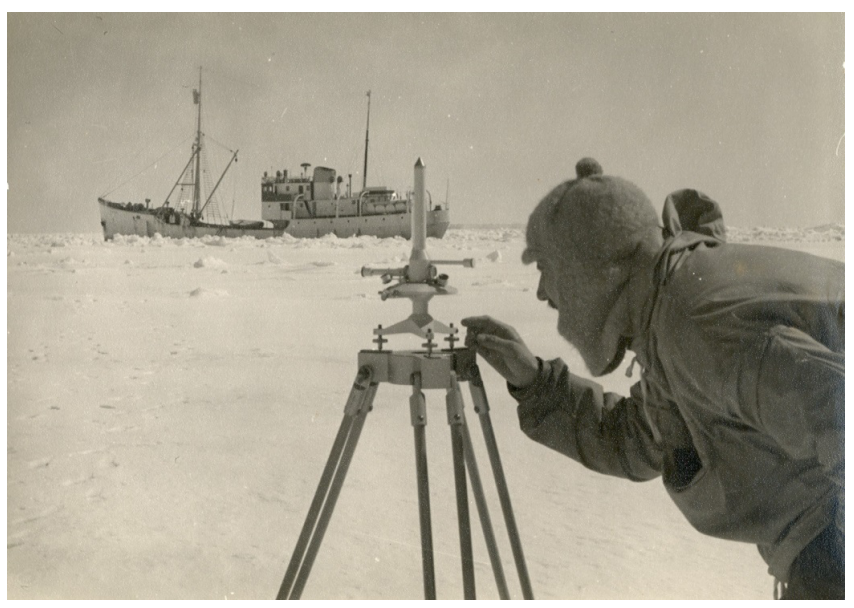

Figure 7. A member of the SANAE 1 expedition to Antarctica in 1960 taking measurements of the horizontal component of the Earth's magnetic field with a quartz horizontal magnetometer (QHM) instrument, with the ship, the Polarhav, in the background.

tor, which has been providing data related to cosmic ray research since 1957, a riometer (relative ionospheric opacity meter, used for the detection of weak radio signals from stars and galaxies) and belonging to the University of Potchefstroom (currently known as the North-West University), was also operated for many years in Hermanus. Today a special FGE three-axis fluxgate magnetometer with an aboveaverage high sensitivity provided by Kyoto University in Japan delivers data on a real-time basis for the detection of magnetic storms. In this way Hermanus Magnetic Observatory is an important observatory providing data for the derivation of the global geomagnetic Dst (Disturbance Storm Time) index since 1957.

\subsection{Science activities}

Hermanus Magnetic Observatory functions as part of the worldwide network of magnetic observatories; its core function in this regard is to monitor and model variations of the Earth's magnetic field. In 2011 Hermanus Magnetic Observatory became part of the newly established South African National Space Agency (SANSA), and the research and geomagnetic activities now form part of the SANSA Space Science Directorate in Hermanus. In 2009 the network of geomagnetic observatories for space weather applications was expanded through the installation of a number of magnetotellurometric (MT) devices in southern Africa (Kotzé et al., 2015). Each device consists of a three-axis fluxgate magnetometer and a two-axis electric field sensor. SANSA's MT network currently has 12 Laboratory of Electromagnetic Innovations (LEMI)-417M MT stations to monitor and measure the long-term variations in the Earth's magnetic and electric fields. Besides its core function of providing geomagnetic field information, the scope of the activities also in- 
cludes fundamental and applied space physics research, postgraduate student training, and science outreach. SANSA in Hermanus is host to the only space weather regional warning centre in Africa which operates as part of the International Space Environment Service (ISES). The magnetic observatories in southern Africa form an integral part in the realtime monitoring of the near-Earth space environment (Kotzé et al., 2015). At present activities also include, but are not limited to, the utilization of data from near-Earth satellites such as Ørsted (Kotzé, 2002), CHAMP (Nahayo and Kotzé, 2012), SWARM and the Cluster mission to study the interaction of the solar wind with the magnetosphere (Kotzé, 2010) and to model the secular variation characteristics of the geomagnetic field of southern Africa, as well as heliospheric satellites including ACE and WIND. In addition, geomagnetic field data from Hermanus, Honolulu, San Juan, and Kakioka are used to derive the Dst index, with Hermanus the sole Southern Hemisphere magnetic observatory of these four stations. Geomagnetic pulsation research, employing both ground-based and satellite observations, is an important activity at SANSA Space Science. At present research is concentrated particularly on $\mathrm{Pi} 2$ pulsations that are closely associated with magnetospheric substorms, and how these pulsations propagate to low latitudes (Sutcliffe, 1997; Sutcliffe and Lühr, 2003). Antarctic research is through a collaborative project utilizing data from the SHARE and SuperDARN radar antenna networks (Ansorge et al., 2017). This involves the British Antarctic Survey (BAS), Johns Hopkins University in the USA, as well as the University of KwaZuluNatal in Durban. Since the first magnetic observatory was founded in Cape Town in 1841, geomagnetism has grown as a scientific discipline in southern Africa, where it is now part of a research programme at SANSA Space Science, involving scientific studies on the Earth's space environment as well as technological applications and products to the benefit of mankind.

Data availability. No data sets were used in this article.

Competing interests. The author declares that he has no conflict of interest.

Special issue statement. This article is part of the special issue "History of geophysical institutes and observatories". It is not associated with a conference.

Acknowledgements. Photographs used in the paper were obtained from the historical archives at SANSA Space Science in Hermanus, South Africa. The author was supported by an NRF grant (no. 103610) for rated researchers.
Edited by: Kristian Schlegel

Reviewed by: Alan Thomson and one anonymous referee

\section{References}

Ansorge, I. J., Skelton, P., Bekker, A., De Bruyn, P. J. N., Butterworth, D., Cilliers, P., Cooper, J., Cowan, D. A., Dorrington, R., Fawcett, S., Fietz, S., Findlay, K. P., Froneman, P. W., Grantham, G. H., Greve, M., Hedding, D., Hofmeyr, G. J. G., Kosch, M., le Roux, P. C., Lucas, M., MacHutchon, K., Meiklejohn, I., Nel, W., Pistorius, P., Ryan, P. G., Stander, J., Swart, S., Treasure, A., Vichi, M., and Jansen van Vuuren, B.: Exploring South Africa's southern frontier: A 20-year vision for polar research through the South African National Antarctic Programme, S. Afr. J. Sci., 113, a0205, https://doi.org/10.17159/sajs.2017, 2017.

Beattie, J. C.: Report of a magnetic survey of South Africa, The Royal Society by Cambridge University Press, London, 1909.

Beattie, J. C. and Morrison, J. T.: The magnetic elements at the Cape of Good Hope from 1605 to 1900, Transactions of the South African Philosophical Society, 14, 1-27, 1903.

De Castro, D. J.: Roteiro de Lisboa a Goa, in: 1968, Obras completes de D. João de Castro Coimbra, edited by: Cortesão, A. and Albuquerque, L., Academia International de Cultura Portuguesa, 2, 1-169, 1538.

De Freycinet, L.: Voyage Atour Du Monde Magnetisme Terrestre, Paris, 1842.

Glass, I. S.: Nicolas-Louis de La Caille, Astronomer and Geodesist, Oxford University Press, 2013.

Grindley, E. N.: The earth's magnetic field in southern Africa at the epoch, 1 July 1930, Royal Soc. London Philos. Trans., 240, 251-294, 1947.

Kotzé, P.: Observatories in Southern Africa, in: Encyclopedia of Geomagnetism and Paleomagnetism, edited by: Gubbins, D. and Herrero-Bervera, E., Springer, Dordrecht, https://doi.org/10.1007/978-1-4020-4423-6, 2007.

Kotzé, P.: CLUSTER and CHAMP satellite observations during the magnetic storm of 21-22 October 2001, Poster presentation at 2010 SuperDarn Workshop, Hermanus, South Africa, 30 May-4 June 2010.

Kotzé, P. B.: Modelling and analysis of Ørsted total field data over Southern Africa, Geophys. Res. Lett., 29, 15, https://doi.org/10.1029/2001GL013868, 2002.

Kotzé, P. B.: Modelling and analysis of southern African geomagnetic field observations: 1840 until 1903, S. Afr. J. Geol., 117, 225-232, https://doi.org/10.2113/gssajg.117.2.225, 2014.

Kotzé, P. B.: The history of geomagnetism and the Hermanus Magnetic Observatory, in: The History of Geophysics in Southern Africa, edited by: de Beer, J. H. SUN Media Stellenbosch, 248 pp., 2015.

Kotzé, P. B., Cilliers, P. J., and Sutcliffe, P. R.: The role of SANSA's geomagnetic observation network in space weather monitoring: A review, Space Weather, 13, 656-664, https://doi.org/10.1002/2015SW001279, 2015.

Kühn, G. J.: Magnetic Observations at Hartebeesthoek 1972-1976, CSIR Report MAG H1, 1978.

La Cour, D.: A vertical-intensity magnetometer, Terr. Magn. Atmos. Electr., 31, 153-163, https://doi.org/10.1029/TE031i004p00153, 1926. 
Linthe, H.-J., Kotzé, P., Mandea, M., and Theron, H.: Keetmanshoop - A new observatory in Namibia, Publications of the Institute of Geophysics, Polish Academy of Sciences, C-99, 38-45, 2007.

Love, J. J. and Chulliat, A.: An International Network of Magnetic Observatories, EOS, 94, 373-384, https://doi.org/10.1002/2013EO420001, 2013.

Nahayo, E. and Kotzé, P. B.: Polynomial modelling of CHAMP satellite data to investigate rapid secular variation fluctuations over southern Africa during 2003 and 2004, Earth Planets Space, 64, 595-603, 2012.

Ogg, A.: Results of observations made at the Magnetic Observatory, University of Cape Town, Trigonometrical Survey Office, 1939.

Pavón-Carrasco, F. J. and De Santis, A.: The South Atlantic Anomaly: The Key for a Possible Geomagnetic Reversal, Front. Earth Sci., 4, 1-9, https://doi.org/10.3389/feart.2016.00040, 2016.

Sabine, E.: Observations made at the magnetical and meteorological observatory at the Cape of Good Hope, Vol. 1, Magnetical observations 1841 to 1846 , London, 1851.
Simpson, J. A.: The cosmic ray nucleonic component: The invention and scientific uses of the neutron monitor, Space Sci. Rev., 93, 11-32, https://doi.org/10.1023/A:1026567706183, 2000.

Sutcliffe, P. R.: Substorm onset identification using neural networks and Pi2 pulsations, Ann. Geophys., 15, 1257-1264, https://doi.org/10.1007/s00585-997-1257-x, 1997.

Sutcliffe, P. R. and Lühr, H.: A comparison of Pi2 pulsations observed by CHAMP in low Earth orbit and on the ground at low latitudes, Geophys. Res. Lett., 30, 2105, https://doi.org/10.1029/2003GL018270, 2003.

Van Wijk, A. M.: Alexander Ogg, 1870-1948, Terr. Magn. Atmos. Electr., 53, 153-154, https://doi.org/10.1029/TE053i002p00153, 1948.

Van Wijk, A. M. and Scheepers, G. L. M.: Magnetic Observations at Tsumeb 1964-1965, Geophysical Series 1, Report No E1 of the Hermanus Geophysical Observatory, Geophysical Branch, Trigonometrical Office, Government Printer, 1969. 